\title{
Investigadores de universidades iberoamericanas idean una plataforma colaborativa de estudio de los paisajes históricos de la producción
}

El laboratorio americano de los paisajes históricos de la producción (applab), iniciativa auspiciada por la Universidad de Sevilla y la Asociación Universitaria Iberoamericana de Postgrado AUIP, surge como plataforma colaborativa de mediación entre investigadores, estudiantes, agentes y ciudadanos que investigan, habitan, gestionan o intervienen en territorios industriales históricos activos o en obsolescencia en América y la Península Ibérica. Inicialmente applab cuenta con la participación de 46 investigadores y el respaldo de 22 instituciones académicas e investigadoras y pretende ofrecer un espacio de experimentación creativa que permita la transferencia simultánea de conocimiento aplicado a la sociedad.

Enrique Larive López | Coordinador Red applab

URL de la contribución <http://www.iaph.es/revistaph/index.php/revistaph/article/view/5058>

El desarrollo que la investigación, protección, valorización y activación del patrimonio industrial ha adquirido en las últimas décadas en América, en sus distintas áreas culturales y socioeconómicas, está en consonancia con lo acontecido en otros ámbitos internacionales, tanto de carácter estatal como de organizaciones transnacionales de protección del patrimonio como Unesco o Icomos.

En paralelo a este incremento del interés por los testimonios materiales e inmateriales de la cultura del trabajo, se han ido produciendo importantes cambios conceptuales en la propia definición de los bienes patrimoniales, como son los de la incorporación de los bienes del Movimiento Moderno, los del patrimonio industrial o los del patrimonio inmaterial. Este proceso puede sintetizarse en relación con unas nuevas dimensiones de los

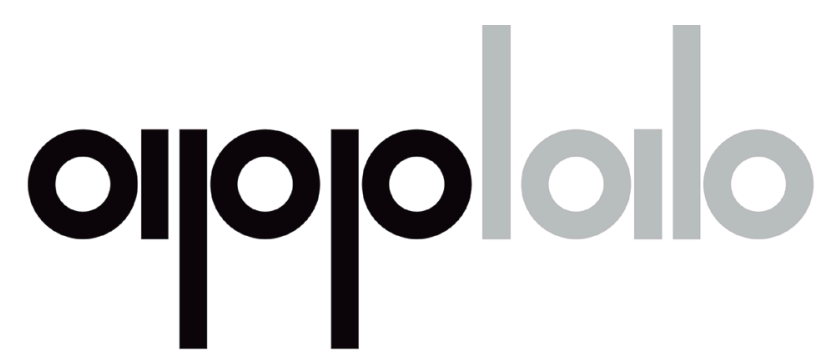

Laboratorio Americano de los Paisajes Históricos de la Producción, applab bienes culturales marcadas por: la mayor representatividad de las temáticas, la territorialización de los testimonios materiales, la superación de la objetualización de los bienes y la ampliación de las cronologías de referencia. Ello se ve constatado por las nuevas fórmulas de protección y de gestión basadas en la interrelación e interacción de los bienes protegidos, mediante los diseños de itinerarios culturales y la caracterización de los paisajes culturales.

El siglo XXI nos enfrenta a nuevos retos respecto de la investigación, la protección y la conservación del patrimonio. Los lazos, cada vez más fuertes entre contextos físicos y afectivos, entre patrimonio natural y cultural, entre patrimonio mueble e inmueble, entre patrimonio material e inmaterial, entre objeto y contexto, entre gestión técnica especializada y participación ciudadana, entre lo urbano y lo rural, entre local y global, entre singular y genérico, entre lo concentrado y lo disperso, nos llevan a una nueva frontera patrimonial.

A esta nueva frontera se aproximan, de una manera desordenada, todas las circunstancias anteriormente señaladas. Por lo que es necesario establecer una nueva topología patrimonial que supere los estrechos marcos metodológicos y conceptuales anteriores. Este nuevo 
territorio patrimonial, mezcla y macla de lo anterior y lo presente, lo definimos con el término conceptual de cliodiversidad.

La cliodiversidad aspira, en una primera fase, a recoger estas intuiciones que todavía aletean sin rumbo cierto en el confuso y agitado panorama de la sociedad globalizada. Y nos sitúan ante la necesidad de diseñar un enfoque integrador de las diversas corrientes del pensamiento y de las demandas sociales, que no sólo desde el ámbito del patrimonio cultural, sino desde otros campos del conocimiento crítico y de la acción sostenible, se están generando en nuestros mundos, en nuestro único mundo.

El patrimonio industrial, como resultado emergente de esta situación descrita, nos ofrece la posibilidad de pensar el patrimonio con unas nuevas herramientas de carácter conceptual, de ensayo metodológico, de práctica instrumental y de gestión activa. Con la intención de generar un laboratorio activo capaz de convertirse en un escenario de acción transdiscipinar que encuentre su profunda razón de ser en los paisajes históricos de la producción, dadas las complejas variables que afectan a estos espacios, entre las que destacamos: los conflictos entre los distintos modelos sociales, las relaciones entre las máquinas y la naturaleza; la dinamicidad como

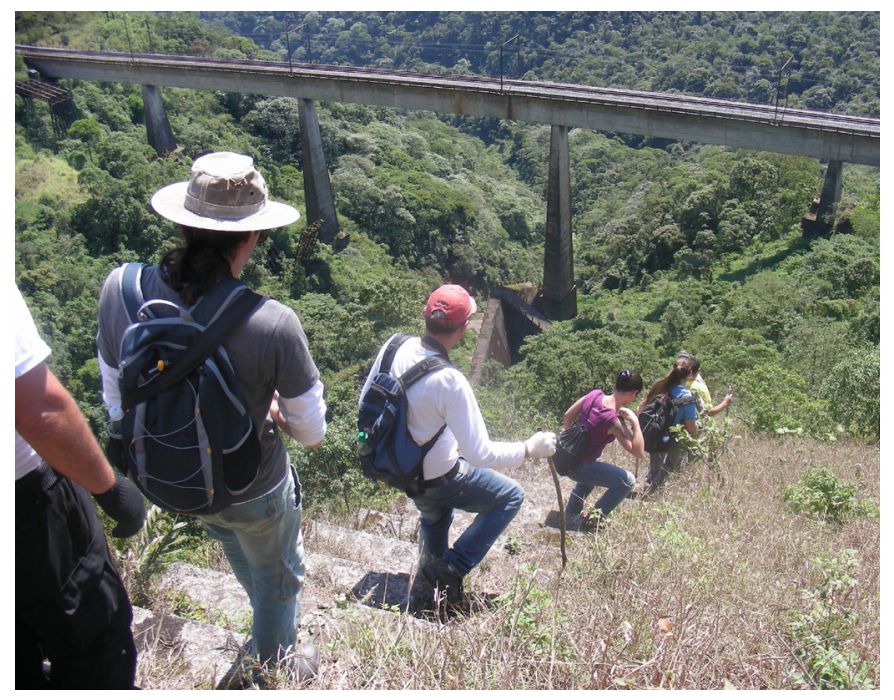

Trabajo de campo en Paranapiacaba con actuales socios de la red applab. São Paulo. Brasil. 2013 | foto Enrique Larive resultado de los constantes cambios que en ellos se operan; la variabilidad de escala; la ruptura de los límites administrativos convencionales; la cliodiversidad que en ellos existe; la ausencia de indicadores de caracterización consensuados; las dificultades para su protección; la necesidad de restablecer la conexión emocional y afectiva entre naturalezas y contextos postindustriales; la complejidad para rastrear las memorias y sus cicatrizaciones, muchas veces contradictorias, ambiguas y dolorosas.

Variables que conforman un territorio dialéctico, acerca del antes, el ahora y el después de lo que convencionalmente entendemos como valores patrimoniales, y que, en estos espacios, ponen de manifiesto las contradicciones existentes entre los usuarios, los propietarios, los gestores, las empresas, las instituciones, los visitantes, las organizaciones conservacionistas, los académicos y los técnicos, en los ámbitos local, regional, nacional e internacional, y, todo ello, desde la propia esencia de los bienes culturales: desde su autenticidad; desde su integridad; desde su documentalidad; desde sus conflictos; desde sus afectividades; desde sus memorias.

\section{Propósito}

El applab es el resultado de distintos encuentros, disertaciones y borradores generados durante las estancias de investigación realizadas en la Universidade Estadual Paulista "Julio de Mesquita Filho", UNESP, en el Estado de São Paulo, en Brasil, durante los años 2013 y 2014 entre los investigadores Julián Sobrino Simal, Enrique Larive López y Eduardo Romero de Oliveira. En ellos se trazan las líneas básicas de un futuro subprograma de investigación que abordará el diseño y puesta en marcha del Laboratorio Americano de los Paisajes Históricos de la Producción.

El laboratorio, applab, pretende ofrecer un espacio de experimentación creativa que permita la transferencia simultánea de conocimiento aplicado a la sociedad, con la intención manifiesta de mejorar la gobernanza de nuestros recursos culturales desde una posición ética que asegure tanto su disfrute armonioso como la resolución de los desafíos a los que se enfrenta la cliodiversidad. 


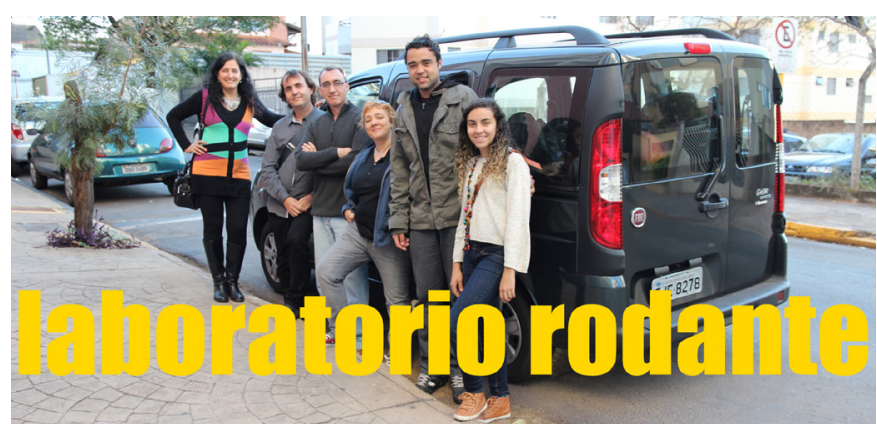

Laboratorio rodante. Proyecto PMF. Bauru. Brasil. 2013 | foto M. ${ }^{\text {a }}$ Victoria Segura

\section{Objetivos}

1. Detectar redes y propiciarlas. Establecer la estructura organizativa para la creación de un canal y punto de intercambio para investigadores dedicados al estudio y gestión de los paisajes históricos de la producción americanos y peninsulares y que desempeñe funciones de carácter consultivo ante instituciones, agrupaciones profesionales y entidades vinculadas.

2. Generar un observatorio de los paisajes históricos de la producción donde propiciar sinergias disciplinares, metodológicas e instrumentales que confluyan en un proceso colaborativo de experimentación, innovación y gestión activa.

3. Establecer un laboratorio abierto donde explorar sistemas e instrumentos de investigación creativa sobre los paisajes históricos de la producción.

4. Ofrecer una plataforma colaborativa de comunicación y transferencia donde favorecer y fomentar la creatividad y la innovación metodológica e instrumental.

5. Fortalecer la cooperación entre investigadores americanos y peninsulares a través del fomento de la investigación colaborativa, integral e inclusiva que favorezca la transferencia de conocimientos, la formación e intercambio entre jóvenes investigadores y la participación.

Desde la experiencia investigadora, académica y profesional de esta comunidad de investigadores e investigadoras (46 investigadores participan inicialmente de esta red) e instituciones académicas (22 instituciones académicas e investigadoras respaldan esta iniciativa) nace applab como plataforma experimental de mediación entre investigación, gestión activa y transferencia. Es un catalizador entre una realidad inactiva, una actividad latente y otra emergente, en un contexto patrimonial entrópico. Es una experiencia abierta a la participación y a la discusión, que pretende propiciar el encuentro entre investigadores de diversos contextos territoriales, académicos y disciplinares y vehicular sinergias e intercambios con jóvenes investigadores y estudiantes de posgrado.

La Red Iberoamericana de Investigación applab está auspiciada por la Universidad de Sevilla y la Asociación Universitaria Iberoamericana de Postgrado AUIP.

\section{Promotores}

Enrique Larive López. Universidad de Sevilla (España) Julián Sobrino Simal. Universidad de Sevilla (España) Eduardo Romero de Oliveira. Universidade Estadual Paulista. (Brasil)

\section{Coordinación}

Enrique Larive López. Universidad de Sevilla. España 